\title{
Outcome of Patients Admitted To PICU and NICU In Relation To PRISM III Score in a Tertiary Care Hospital
}

\author{
Khaleelullah MD Shakil ${ }^{\oplus 1}$, Pavan D. Kumar ${ }^{\circledR 2}$, Sreenivasa B. ${ }^{\circledR 3}$, Talatam Sivachand ${ }^{\odot 4}$ \\ ${ }^{1}$ Assistant Professor, Department of Pediatrics, Basaveshwara Medical College Hospital and Research Centre, Chitradurga, Karnataka, India, ${ }^{2}$ Associate Professor, \\ Department of Pediatrics, DM Wayanad Institute of Medical Sciences, Meppadi, Wayanad, Kerala, India, ${ }^{3}$ Professor, Department of Pediatrics, Basaveshwara Medical \\ College Hospital and Research Centre, Chitradurga, Karnataka, India, ${ }^{4}$ Senior Resident, Department of Pediatrics, Basaveshwara Medical College Hospital and Research \\ Centre, Chitradurga, Karnataka, India.
}

\section{Abstract}

Introduction: Pediatric intensive care units (PICU) are an indispensable component of a successful health care establishment. They play a crucial part in reducing morbidity and mortality in the adolescent group. Several models and scores have been tried for internal auditing and in detecting the case fatality rate of a patient admitted in PICU and NICU. This helps the clinician in triaging patient care as and when required. The PRISM III score is widely used in PICU and NICU for the same. To evaluate the validity of the PRISM III score in predicting mortality in children admitted to PICU and NICU in a tertiary care hospital and to predict the probability of death of various PRISM III scores. Subjects and Methods: 260 patients admitted to PICU and NICU were included in the study after obtaining informed consent from parents/guardians. Each patient was evaluated for the parameters in the PRISM III score and blood was drawn to send for investigations and results were entered in the proforma and were evaluated. Results: There was an increase in mortality rate with raise in PRISM III score. PRISM III offered a fair predictive power with the area under the curve 0.7 with $95 \%$ C.I. Out of 260 patients included in the study $24(9.2 \%)$ were dead. Variables like systolic BP, abnormal mental status, pupillary reflex, acidosis, and low platelet counts were significantly associated with a higher mortality rate. Conclusion: Evaluation of mortality and outcome of a patient admitted in PICU in a tertiary care hospital is best predicted by PRISM III score.

Keywords: PRISM III scores, PICU, NICU, Mortality rate

Corresponding Author: Pavan D. Kumar, Associate Professor, Department of Pediatrics, DM Wayanad Institute of Medical Sciences, Meppadi, Wayanad, Kerala, India.

E-mail: pavaniams@gmail.com

Received: 02 September 2020

Revised: 19 October 2020

Accepted: 26 October 2020

Published: 28 December 2020

\section{Introduction}

Each year about 27 million children are born in India. Around $10 \%$ do not survive till the age of 5yrs. India is contributing to $25 \%$ of over 5.9 million under 5 deaths occurring worldwide every year. ${ }^{[1]}$ The overall mortality in the PICU is estimated at approximately $3 \%{ }^{[2]}$ Over the past three decades with rapid growth in the management of critically ill patients and the latest advances in the medical field, there is a need for predicting the risk of mortality in patients admitted to PICU and also to analyze the outcome of these patients. This has become a demanding job for the current day resuscitator. [3] The demand for highly developed apparatus and modest treatment of critically ill patients is already well established. Likelihood models that estimate the risk of mortality provide a fairly reasonable and ideal way to evaluate the severity of sickness in patients admitted to PICU. The Pediatric Risk of
Mortality (PRISM III) Score has been developed to enable the physician to determine the possible outcome and risk of death of the patients on intensive care management. ${ }^{[4]}$ It helps in forming the selection criteria for patients who might need such management and also improve the judgment skills of the caregiver in NICU and PICU. ${ }^{[5]}$ Determining the mortality in children admitted to PICU and NICU at the tertiary care hospitals under Indian circumstances is the main motive of this study.

\section{Subjects and Methods}

The Aims and objectives of this study are to evaluate the accuracy of the PRISM III score in predicting mortality in children admitted to PICU and NICU in a tertiary care hospital and to determine the prediction of the probability of death of various PRISM III scores. This was a prospective study 
conducted for a period of 18 months $\left(1^{\text {st }}\right.$ December 2017 to $30^{\text {th }}$ May 2019) in a tertiary care Hospital. All patients admitted to NICU and PICU were involved after obtaining written informed consent. Children who got discharged from PICU within 24 hours of admission, those with congenital malformations and those who succumbed to death within 8 hours of admission were excluded from the study. Neonates admitted in NICU and those from 1 month to 18 years of age admitted to the pediatric intensive care unit were enrolled in the study within 24 hours of admission. The questionnaire captured the demographic data, the primary system affected by the disease among other parameters. Data were collected and entered in Microsoft XL sheet, later analyzed using statistical SPSS 20 software, appropriate statistical tests were applied and data were analyzed. Based on the age and magnitude of the disease, the PRISM III score has 14 physiological and 34 laboratory parameters. These include serum levels of potassium, calcium and bilirubin, respiratory rate and heart rate, systolic and diastolic blood pressure, mental status of the patient assessed by Glasgow coma scale, serum bicarbonate deficit, blood glucose levels, prothrombin and partial thromboplastin time and partial pressure of oxygen and carbon dioxide.

\section{Results}

Out of 260 patients, $35 \%$ were neonates, $23 \%$ were infants, $34 \%$ were children and $8 \%$ were adolescents [Graph No 1]. 166 were males and 94 were females.

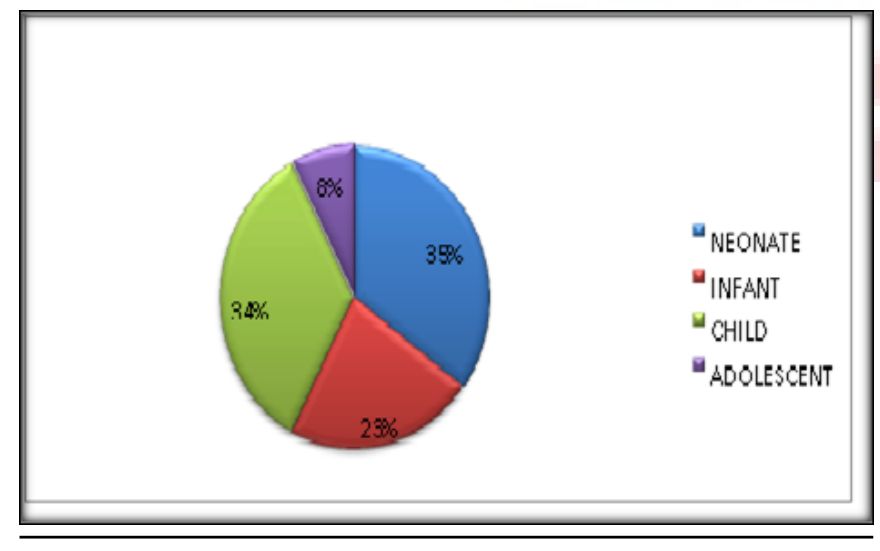

\section{Graph 1: Pie Diagram Showing Age-Wise Distribution}

Out of 260 patients, $40 \%$ of cases had Respiratory involvement, $37 \%$ had central nervous involvement, $3 \%$ had cardiovascular involvement, $1 \%$ had renal involvement and $19 \%$ had other involvement including infectious diseases and sepsis [Graph No 2].

In this study, 0 and 33 was the minimum and maximum PRISM score obtained respectively. The mean, median and mode were

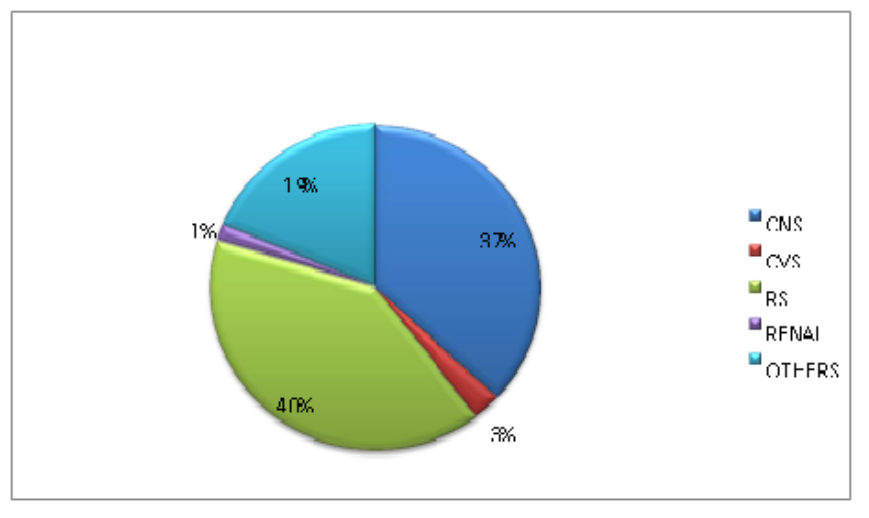

Graph 2: Pie diagram showing system affected

10.36, 9 and 3 respectively. Maximum cases had a score between 3 and 5 [Graph No 3].

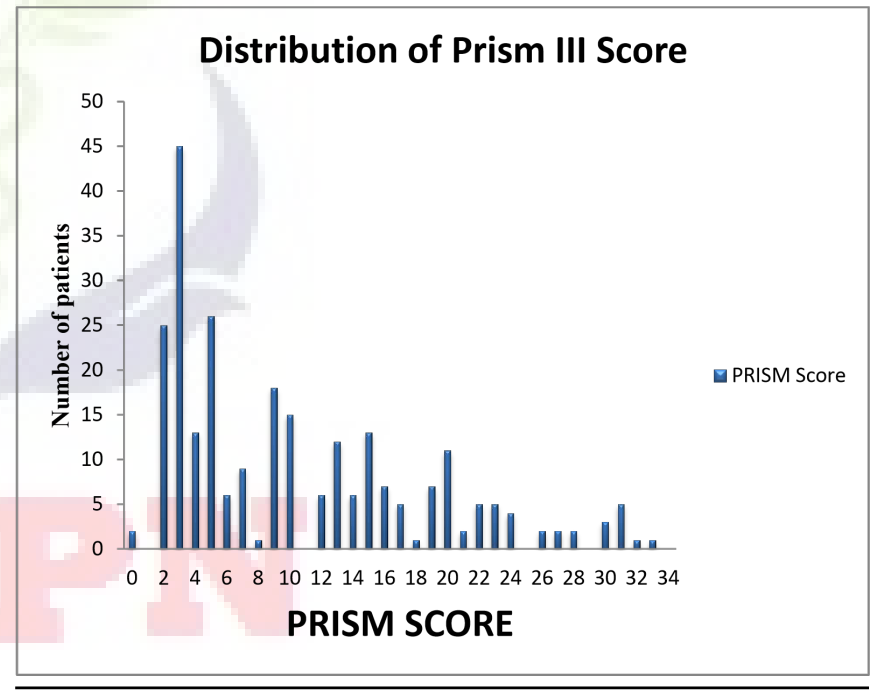

Graph 3: Bar diagram showing the distribution of the PRISM III score

In the present study, at score $0-5$, there was no mortality, at score 6-10 mortality rate was $2 \%$, at score $11-15$ mortality rate was $5.4 \%$, at score $16-20$ mortality rate was $22.6 \%$ at score $>20$ mortality rate was $43.8 \%$. This study shows an increase in the risk of mortality found to be increasing with the increase in scores. This study analysis shows a statistically significant association of prism score with risk of mortality [Table No 1].

The accuracy of any scoring model is best assessed by the area under the curve (ROC curve). The test is more precise if the ROC curve is close to 1 . In our study, the ROC is 0.7 indicating the test to be a good tool in assessing mortality [Graph No 4].

Out of 260 patients, 94 patients had CNS involvement and $6.7 \%$ of patients were dead, 107 patients had RS involvement 


\begin{tabular}{|c|c|c|c|}
\hline \multirow[t]{2}{*}{ PRISM III } & \multicolumn{2}{|c|}{ Nature of outcome } & \multirow[t]{2}{*}{ Total } \\
\hline & Alive & Dead & \\
\hline $0-5$ & $111(100 \%)$ & $0(0 \%)$ & $111(100 \%)$ \\
\hline $6-10$ & $48(98 \%)$ & $1(2 \%)$ & $49(100 \%)$ \\
\hline $11-15$ & $35(94.6 \%)$ & $2(5.4 \%)$ & $37(100 \%)$ \\
\hline $16-20$ & $24(77.4 \%)$ & $7(22.6 \%)$ & $31(100 \%)$ \\
\hline $\begin{array}{l}\text { More than } \\
20\end{array}$ & $18(56.2 \%)$ & $14(43.8 \%)$ & $32(100 \%)$ \\
\hline Total & $236(90.8 \%)$ & $24(9.2 \%)$ & $260(100 \%)$ \\
\hline
\end{tabular}

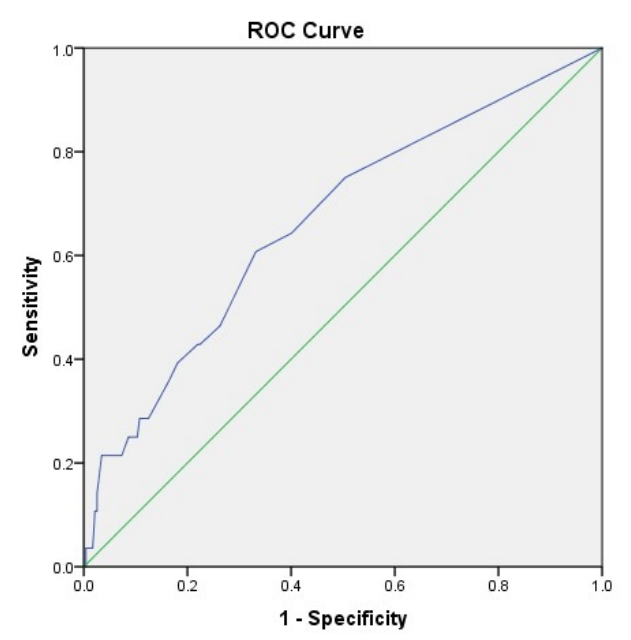

Diagonal segments are produced by ties.

\section{Graph 4: Showing ROC Curve}

and $9.4 \%$ were dead and 48 had other causes like infectious diseases, sepsis, DKA and $6.25 \%$ were dead. There was no statistical significance. Graph No 5 shows the system involved and the nature of the outcome.

Out of 260 cases, 41 cases had low systolic BP. Children with shock were analyzed with those who did not present with shock and showed significant association with mortality [Table No 2].

\begin{tabular}{|llll}
\hline \multicolumn{4}{|l}{ Table 2: Nature of outcome and Systolic BP } \\
\hline SBP Score & \multicolumn{2}{l}{ Nature of outcome } & Total \\
& Alive & Dead \\
\hline 0 & $203(92 \%)$ & $16(8 \%)$ & $219(100 \%)$ \\
\hline 3 & $25(86.2 \%)$ & $4(13.8 \%)$ & $29(100 \%)$ \\
7 & $8(66.7 \%)$ & $4(33.4 \%)$ & $12(100 \%)$ \\
\hline Total & $236(90.8 \%)$ & $24(9.2 \%)$ & $260(100 \%)$ \\
\hline
\end{tabular}

\section{Chi-Square value 10.009.P value 0.007 (significant).}

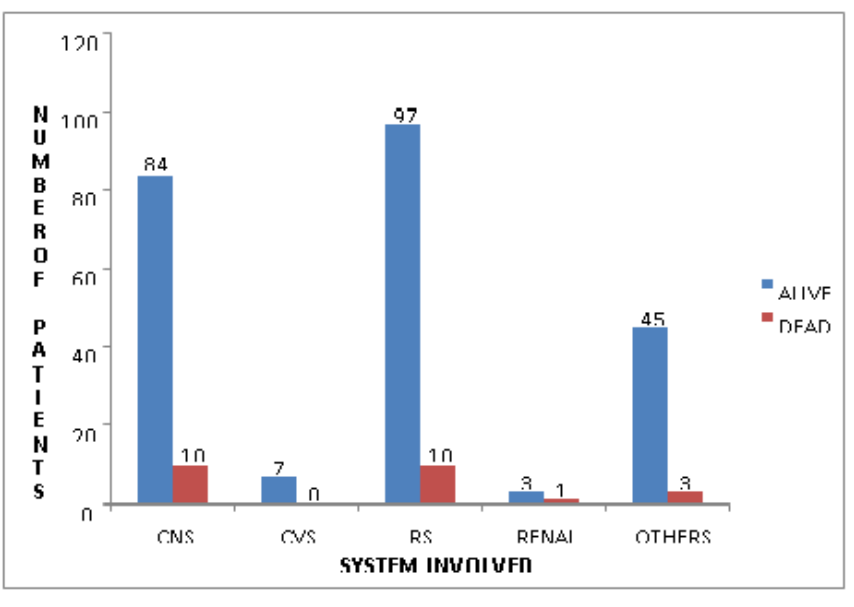

Graph 5: Bar diagram showing Nature of outcome and System Involved Components of prism III score \& nature of the outcome

Parameters like abnormal papillary reflex, altered GCS, acidosis, platelet count showed statistically significant association with mortality when analyzed with those with normal values.

Components of Prism III score like abnormal heart rate, temperature, total $\mathrm{CO} 2$, ph, serum glucose, $\mathrm{PaO} 2, \mathrm{PaCO}$, serum potassium, serum creatinine, blood urea nitrogen, WBC count and PT/aPTT levels when compared with their normal counterparts failed to show any statistical significance.

The goodness of the predictive model

The Hosmer and Lemeshow fitness of good test provided a fairly better evaluation of PRISM III SCORE. [Table No 3]

\section{Discussion}

Audits in ICU and utilization of models for scoring have not been extensively described in our country. With the improvement in intensive care facilities and the high cost associated with intensive care, there should be rational use of resources and for identifying sick patients there should be a scoring system that was addressed by few studies in our country. In our study out of 260 patients, $166(63.85 \%)$ were males and 94(36.15\%) are females. Death was observed in $24(9.2 \%)$ patients, 8 are females $(33.3 \%)$ and 16 are females $(66.7 \%)$. At our center, we found that mortality is $9.2 \%$ which was comparatively less than the study conducted in India by Varma A et al (14.8\%). ${ }^{[6]}$ Bhatia et al had a mortality rate of $24.7 \%$ which is more than studies conducted in the western countries. ${ }^{[7]}$

In our study, the performance of PRISM III score showed a fair prediction of mortality with the receiver operating curve analysis showing 0.7 (70\% correct prediction) areas under 


\begin{tabular}{|llllll|}
\hline \multicolumn{7}{l}{ Table 3: Showing Goodness of the Predictive Model. Hosmer-Lemeshow Test } \\
\hline PRISM III & ALIVE & \multicolumn{5}{l}{ DEAD } & TOTAL \\
\hline & Observed & Expected & Observed & Expected & \\
\hline-5 & 111 & 110.550 & 0 & 0.450 & 111 \\
\hline $6-10$ & 48 & 48.247 & 1 & 0.753 & 49 \\
\hline $11-15$ & 35 & 34.915 & 2 & 2.085 & 37 \\
\hline $15-20$ & 24 & 25.229 & 7 & 5.771 & 31 \\
\hline$>20$ & 18 & 17.059 & 14 & 14.941 & 32 \\
\hline TOTAL & 236 & 236 & 24 & 24 & 260 \\
\hline
\end{tabular}

Table 4: Showing Comparison of Various Studies

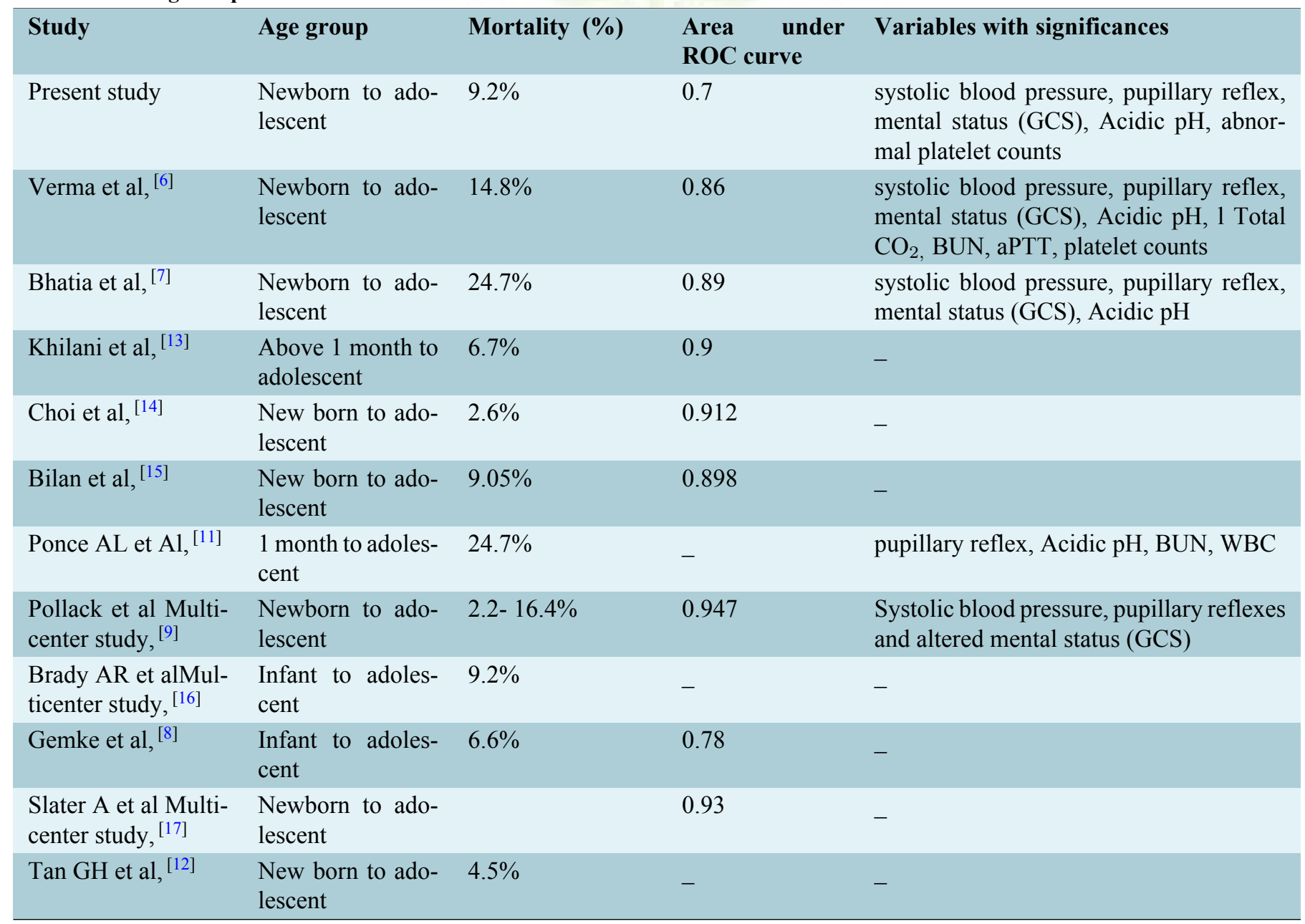


the curve with a $95 \%$ confidence interval which is similar to the study conducted by Gemke et al, ${ }^{[8]}$ where the area under ROC curve is 0.78 . In a study conducted by Pollack et $\mathrm{al}^{\left[{ }^{[9]}\right.}$ for designing PRISM III score area ROC curve is 0.947. In our study, the PRISM III score showed an increase in mortality which was proved in many other studies. An increase in PRISM III score in different organ systems is associated with an increase in mortality. This was also shown in a study conducted by Fargason et al where PRISM score was used to assess patients with renal failure, but based on the prediction of poor outcome a decision of withholding dialysis cannot be made. ${ }^{[10]}$ In our study patient with a PRISM III score of 31 survived so we could not stop life-supporting measures with high scores. In this study among different variables minimum systolic blood pressure, abnormal pupillary reflex, abnormal mental status $(\mathrm{GCS}<8)$, acidic $\mathrm{pH}$, abnormal platelet counts had a statistically significant association with mortality. In a study conducted by Pollack et al which is a multicentric study for designing of PRISM III score, there was a notable interrelation with mortality among minimum systolic blood pressure, abnormal pupillary reflex, abnormal mental status $(\mathrm{GCS}<8) .{ }^{[9]}$ In a study conducted by Ponce AL et al, abnormal pupillary reflex, Acidic $\mathrm{pH}$, abnormal BUN, abnormal WBC counts were significantly associated with mortality. ${ }^{[11]}$ In a study conducted by Tan GH et al minimum systolic blood pressure, abnormal pupillary reflex, abnormal mental status $(\mathrm{GCS}<8)$ were significantly associated with mortality. ${ }^{[12]}$

\section{Conclusion}

This study concludes that the evaluation of mortality and outcome of a patient admitted in PICU in a tertiary care hospital is best predicted by PRISM III score. The application of scoring systems in PICU and NICU helps in auditing and also in explaining the prognosis of the child to the parents. Scoring systems with lesser laboratory parameters are needed in our country without compromising on predictability.

\section{References}

1. Sankar MJ, Neogi SB, Sharma J, Chauhan M, Srivastava R, Prabhakar PK, et al. State of newborn health in India. J Perinatol. 2016;36(Suppl 3):S3-S8. Available from: https: //dx.doi.org/10.1038/jp.2016.183.

2. Carter BS, Howenstein M, Gilmer MJ, Throop P, France D, Whitlock JA. Circumstances surrounding the deaths of hospitalized children: opportunities for pediatric palliative care. Pediatrics. 2004;114(3):361-367. Available from: https://doi. org/10.1542/peds.2003-0654-f.

3. Fiser D. Textbook of Pediatric Intensive Care. Rogers M, G ND, editors; 1996.
4. Pollack MM, Ruttimann UE, Getson PR. Pediatric risk of mortality (PRISM) score; 1988. Available from: https://dx.doi. org/10.1097/00003246-198811000-00006.

5. Shann F, Pearson G, Slater A, Wilkinson K. Paediatric index of mortality (PIM): a mortality prediction model for children in intensive care; 1997. Available from: https://dx.doi.org/10. 1007/s001340050317.

6. Varma A, Damke S, Meshram R, Vagha J, Kher A, Vagha K. Prediction of mortality by pediatric risk of mortality (PRISM III) score in teriary care rural hospital in India. Int J Contemp Pediatr. 2017;4(2):322-322. Available from: https://dx.doi.org/ 10.18203/2349-3291.ijcp20170003.

7. Bhatia RC, Singh D, Gautam A, Pooni PA, Shimar TS. NCPCC 2005 - Conference Abstracts. 2006;5:3-3.

8. Gemke RJ, van Vught JA. Scoring systems in pediatric intensive care: PRISM III versus PIM. Intensive Care Med. 2002;28(2):204-207. Available from: https://dx.doi.org/10. 1007/s00134-001-1185-2.

9. Pollack MM, Patel KM, Ruttimann UE. PRISM III; 1996. Available from: https://dx.doi.org/10.1097/00003246199605000-00004.

10. Fargason CA, Langman CB. Limitations of the pediatric risk of mortality score in assessing children with acute renal failure; 1993. Available from: https://dx.doi.org/10.1007/bf01213327.

11. Ponce AL. Simplified PRISM III score and outcome in the pediatric intensive care unit. Pediatr Int. 2005;47(1):80 83. Available from: https://doi.org/10.1111/j.1442-200x.2004. 01997.x

12. Tan GH, Tan TH, Goh DY, Yap HK. Risk factors for predicting mortality in a pediatric intensive care unit. Ann Acad Med. 1998;27(6):813-821.

13. Khilnani P, Sarma D, Singh R, Uttam R, Rajdev S, Makkar A, et al. Demographic profile and outcome analysis of a tertiary level pediatric intensive care unit. Indian J Pediatr 2004;71(7):587-591. Available from: https://dx.doi.org/10. 1007/bf02724117.

14. Choi KM, Ng DK, Wong SF, Kwok KL, Chow PY, Chan CH, et al. Assessment of the Pediatric Index of Mortality (PIM) and the Pediatric Risk of Mortality (PRISM) III score for prediction of mortality in a pediatric intensive care unit in Hong Kong. Hong Kong Med J. 2005;11(2):97-103.

15. Bilan N, Galehgolab BA, Emadaddin A, Shiva S. Risk of Mortality in Pediatric Intensive Care Unit, Assessed by PRISMIII. Pak J Biol Sci. 2009;12(6):480-485. Available from: https://dx.doi.org/10.3923/pjbs.2009.480.485.

16. Brady AR, Harrison D, Black S, Jones S, Rowan K, Pearson $\mathrm{G}$, et al. Assessment and optimization of mortality prediction tools for admissions to pediatric intensive care in the United Kingdom. Pediatrics. 2006;117(4):733-775. Available from: https://doi.org/10.1542/peds.2005-1853.

17. Slater A, Shann F. The suitability of the Pediatric Index of Mortality (PIM), PIM2, the Pediatric Risk of Mortality (PRISM), and PRISM III for monitoring the quality of pediatric intensive care in Australia and New Zealand. Pediatr Crit Care Med. 2004;5(5):447-454. Available from: https://dx.doi.org/ 10.1097/01.pcc.0000138557.31831.65. 
Copyright: (C) the author(s), 2020. It is an open-access article distributed under the terms of the Creative Commons Attribution License (CC BY 4.0), which permits authors to retain ownership of the copyright for their content, and allow anyone to download, reuse, reprint, modify, distribute and/or copy the content as long as the original authors and source are cited.

How to cite this article: MD Shakil K, Kumar PD, B. S, Sivachand T. Outcome of Patients Admitted To PICU and NICU In Relation To PRISM III Score in a Tertiary Care Hospital. Asian J. Clin. Pediatr. Neonatol. 2020;8(4):13-18.

DOI: dx.doi.org/10.47009/ajcpn.2020.8.4.4

Source of Support: Nil, Conflict of Interest: None declared. 